\title{
Keragaman Lamun (Seagrass) di Pesisir Desa Lihunu Pulau Bangka Kecamatan Likupang Kabupaten Minahasa Utara, Sulawesi Utara
}

\section{Zakiah Susanti Kamaruddin a*, Sendy B. Rondonuwu i a, Pience Veralyn Maabuat a}

aJurusan Biologi, FMIPA, Unsrat, Manado

\begin{tabular}{l}
\hline K A T A K U N C I \\
keanekaragaman \\
lamun \\
Lihunu \\
Pulau Bangka
\end{tabular}

\begin{abstract}
A B S T R A K
Lamun adalah tumbuhan berbunga yang dapat tumbuh dengan baik pada lingkungan laut dangkal. Penelitian ini dilaksanakan di Pesisir Desa Lihunu dengan menggunakan metode purposive random sampling yang dilaksanakan pada bulan Agustus 2015 saat surut terendah. Analisis data meliputi perhitungan dengan menggunakan rumus menurut Shannon \& Wienner dan buku identifikasi lamun. Berdasarkan hasil penelitian terdapat tujuh jenis lamun yang ditemukan yaitu, Enhalus acoroides (L.f.) Royle, Thalassia hemprichii (Ehrenberg) Ascherson, Cymodocea rotundata (Ehrenberg) Ascherson, Cymodocea serrulata (R. Brown) Ascherson, Halophila ovalis (R. Brwon) Hooker, Halodule pinifolia (Miki) den Hartog dan Syringodium isoetifolium (Ascherson) Dandy. Lamun Enhalus acoroides dan Thalassia hemprichii memiliki penyebaran terluas, karena ditemukan di seluruh transek pada lokasi penelitian. Jenis yang jarang dijumpai adalah Halophila ovalis dan Cymodocea serrulata. Jumlah individu lamun yang ditemukan adalah 2316 individu. Nilai indeks keanekaragaman di Pesisir Desa Lihunu memperlihatkan bahwa di wilayah ini keanekaragaman jenis lamun sedang dengan $H^{\prime}=1 \leq H^{\prime} \leq 3$.
\end{abstract}

\section{KE YWOR DS}

diversity

seagrass

Lihunu

Bangka Island

\begin{abstract}
A B S T R A C T
Seagrass is flowering plants that can grow so well in shallow marine environments. This research was conducted in Seashore Lihunu Village on August 2015 using field observation with purposive random sampling when low withdraw. Data analysis was performed using the formula of Shannon-Wienner and identification of seagrass. Results obtained in this research showed that there are seven types of seagrass, namely Enhalus acoroides (L.f) Royle, Thalassia hemprichii (Ehrenberg) Ascherson, Cymodocea rotundata (Ehrenberg) Ascherson, Cymodocea serrulata (R. Brown) Ascherson, Halophila ovalis (R. Brwon) Hooker, Halodule pinifolia (Miki) den Hartog and Syringodium isoetifolium (Ascherson) Dandy. Enhalus acoroides and Thalassia hemprichii have wide distribution because they can be found in all transect line at research site. Species that are rarely found are Halophila ovalis and Cymodocea serrulata. Number of individual found was 2316 individuals. Value of diversity index at Seashore Lihunu Village showed that this area has moderate seagrass diversity with $\mathrm{H}^{\prime}=1 \leq \mathrm{H}^{\prime} \leq 3$.
\end{abstract}

TERSEDIA ONLINE

01 Februari 2016

*Corresponding author: Jurusan Biologi FMIPA UNSRAT, Jl. Kampus Unsrat, Manado, Indonesia 95115; Email address: ucankamaruddin@yahoo.co.id Published by FMIPA UNSRAT (2016) 


\section{Pendahuluan}

Lamun merupakan tumbuhan tingkat tinggi (Magnoliophyta) yang dapat menyesuaikan diri hidup terbenam di laut dangkal (Wood et al., 1969). Faktor utama yang dapat membedakan lamun dengan jenis tumbuhan lainnya, seperti rumput laut (seaweed) yaitu keberadaan bunga dan buahnya yang tampak sangat jelas sehingga antara lamun dan rumput laut bisa dibedakan dengan mudah (Nainggolan, 2011). Di perairan pantai, lamun tumbuh membentuk padang yang terdiri dari satu jenis sampai beberapa jenis yang disebut padang lamun. Padang lamun merupakan suatu ekosistem di kawasan pesisir yang memiliki tingkat keanekaragaman hayati yang cukup tinggi dan sebagai penyumbang nutrisi yang sangat berpotensial bagi perairan disekitarnya karena memiliki tingkat produktivitas yang tinggi. Ekosistem padang lamun memberikan habitat bagi biota laut. Disebut padang lamun karena ekosistem padang lamun tersebut berasosiasi dengan berbagai jenis biota laut yang bernilai sangat penting dengan tingkat keragamannya yang tinggi (Nainggolan, 2011). Ekosistem lamun mempunyai peranan yang sangat penting dalam menunjang kehidupan dan perkembangan biota di laut dangkal. Menurut Bengen (2011) dalam Nur (2011), dalam hasil penelitiannya diketahui bahwa peranan lamun di lingkungan perairan laut dangkal yaitu, produsen, penangkap Sedimen dan pendaur zat hara.

Pantai Lihunu merupakan salah satu pantai di Kecamatan Likupang yang memiliki keanekaragaman biota laut salah satu di antaranya yaitu lamun. Di lokasi ini dekat dengan pemukian warga, sering dijadikan tempat wisata bagi para wisatawan baik mancanegara maupun domestik. Kapal dan perahu nelayan sering melewati lokasi tersebut mengingat mata pencaharian warga setempat sebagai nelayan selain bertani dan menjalankan transportasi laut. Aktifitas tersebut secara tidak langsung dapat mengganggu keberadaan lamun itu sendiri,seperti terlihat jelas di sekeliling lokasi banyak lamun yang mati. Faktor lainnya yang menyebabkan areal yang menjadi habitat lamun semakin sedikit, antara lain pemukiman warga, perikanan dan pariwisata (Dahuri, 2001). Oleh karena itu penelitian untuk mengetahui keanekaragaman lamun di Pantai Lihunu Kecamatan Likupang Kabupaten Minahasa Utara dengan menghitung nilai indeks keanekaragamannya penting untuk dilakukan.

\section{Bahan dan Metode}

Pengambilan data di lapangan pada waktu surut terendah dan telah dilaksanakan pada bulan Juni 2015 di Pulau Bangka tepatnya di Desa Lihunu Kecamatan Likupang Timur Kabupaten Minahasa Utara. Berdasarkan informasi pemerintah setempat Desa Lihunu memiliki luas $5 \mathrm{Ha}$. Lokasi penelitian dibagi menjadi tiga stasiun yaitu stasiun 1 berada dekat pemukiman warga lebih tepatnya di belakang pemukiman warga dengan titik koordinat $\mathrm{N}$ : $01^{\circ} 45^{\prime} 31.32^{\prime \prime} \mathrm{E}: 1^{\circ} 05^{\circ} 58.57^{\prime \prime}$, stasiun 2 di area mangrove dekat dengan dermaga dengan titik koordinat $\mathrm{N}: 01^{\circ} 45^{\prime} 18.80^{\prime \prime} \mathrm{E}: 1^{\circ} 5^{\circ} 08^{\prime} 49.81^{\prime \prime}$ dan stasiun 3 letaknya di kawasan mangrove dengan titik koordinat N : 01 ${ }^{\circ} 45^{\prime} 18.13^{\prime \prime} \mathrm{E}: 125^{\circ} 08^{\prime} 50.40 "$. Alat dan bahan yang digunakan dalam penelitian ini adalah GPS, stopwatch, alat tulis menulis, patok kayu, tali plastik 2 warna, meteran 100 m, parang, keping secchi, kertas $\mathrm{pH}$, termometer, salinometer, kamera, plastik sampel, sarung tangan, kuadarat plot 1x1 m², ember kecil dan buku identifikasi.

Metode yang digunakan dalam penelitian ini yaitu Purposive Random Sampling yaitu dengan membuat garis transek dan kuadrat $1 \times 1 \mathrm{~m}^{2}$. Ada 3 garis transek yang dibuat dengan panjang masingmasing transek yaitu $100 \mathrm{~m}$ dan jarak setiap garis transek adalah $100 \mathrm{~m}$. Pada setiap garis transek dibuat 10 titik plot dengan jarak masing-masing plot $10 \mathrm{~m}$ untuk meletakkan kuadrat $1 \times 1 \mathrm{~m}^{2}$. Jadi total seluruh plot pada 3 transek adalah 30 titik/plot kuadrat. Pengambilan sampel dan data lamun dilakukan dengan menggunakan metode transek kuadrat yang dilakukan pada waktu surut terendah siang hari. Jenis lamun yang ditemukan diidentifikasi berdasarkan karakteristik morfologi yang mengacu pada referensi buku dari Den Hartog (1970) dan Philips dan Menez (1988). Analisis data mencakup kerapatan jenis, kerapatan jenis relatif, frekuensi jenis, frekuensi jenis relatif, penutupan jenis, penutupan jenis relatif serta indeks nilai penting (INP) untuk menduga keseluruhan dari peranan suatu jenis lamun. Indeks keanekaragaman $(H)$ menggunakan rumus menurut Shannon \& Weaner (Magurran, 1988).

$$
\mathrm{H}^{\prime}=-\sum \mathrm{Pi} \ln \mathrm{Pi}
$$

dengan $\mathrm{H}^{\prime}=$ keanekakeragaman Shannon-Wienner ; $\mathrm{Pi}=\mathrm{ni} / \mathrm{N}$; ni = jumlah individu dari suatu jenis ke-i ; $\mathrm{N}=$ Jumlah total individu seluruh jenis.

\section{Hasil dan Pembahasan}

Data yang diperoleh di lapangan dilakukan analisis data mengenai nilai kerapatan, kerapatan relatif, frekuensi, frekuensi relatif, penutupan, penutupan relatif dan Indeks Nilai Penting (INP) di Pesisir Desa Lihunu disajikan dalam tabel.

Berdasarkan hasil analisis data di atas menunjukkan kerapatan jenis lamun tertinggi di transek I yaitu S. isoetifolium sebanyak 170 individu/ $\mathrm{m}^{2}$ dengan kerapatan relatifnya $28.24 \%$ dan jenis lamun yang memiliki nilai kerapatan terendah yaitu $H$. pinifolia hanya 4 individu/m² dengan kerapatan relatifnya $0.66 \%$. Transek II nilai kerapatan tertinggi yaitu $T$. hemrpichii sebanyak 264 individu/ $\mathrm{m}^{2}$ dengan kerapatan relatifnya 29.80\% dan nilai kerapatan terendah di transek ini yaitu S. isoetifolium sebanyak 61 individu/m² dengan kerapatan relatifnya $6.88 \%$. 
Tabel 1. Nilai Kerapatan, Kerapatan Relatif, Frekuensi, Frekuensi Relatif, Penutupan, Penutupan Relatif dan INP pada transek I, II dan III.

\begin{tabular}{|c|c|c|c|c|c|c|c|c|c|}
\hline \multirow{2}{*}{ No. } & \multicolumn{9}{|l|}{ Transek I } \\
\hline & Jenis & $\mathrm{K}$ & $\mathrm{KR}(\%)$ & $\mathrm{Pi}$ & $\mathrm{F}$ & FR (\%) & $\mathrm{P}(\%)$ & PR (\%) & INP \\
\hline 1 & Thalassia hemprichii & 88 & 14.62 & 9 & 0.90 & 23.68 & 11.56 & 22.58 & 60.88 \\
\hline 2 & Enhalus acoroides & 130 & 21.59 & 10 & 1.00 & 26.32 & 19.24 & 37.58 & 85.49 \\
\hline 3 & Syringodium isoetifolium & 170 & 28.24 & 4 & 0.40 & 10.53 & 4.6 & 9.00 & 47.77 \\
\hline 4 & Halodule pinifolia & 4 & 0.66 & 1 & 0.10 & 2.63 & 0.38 & 0.74 & 4.04 \\
\hline 5 & Cymodocea rotundata & 164 & 27.24 & 7 & 0.70 & 18.42 & 9.30 & 18.16 & 63.83 \\
\hline \multirow[t]{2}{*}{6} & Cymodocea serrulata & 46 & 7.64 & 7 & 0.70 & 18.42 & 6.11 & 11.93 & 38.00 \\
\hline & Total & 602 & 100 & 38 & 3.80 & 100 & 51.20 & 100 & 300 \\
\hline \multicolumn{10}{|c|}{ Transek II } \\
\hline 1 & Thalassia hemprichii & 264 & 29.80 & 10 & 1.00 & 23.81 & 19.52 & 37.12 & 90.72 \\
\hline 2 & Enhalus acoroides & 139 & 15.69 & 7 & 0.70 & 16.67 & 11.92 & 22.67 & 55.02 \\
\hline 3 & Syringodium isoetifolium & 61 & 6.88 & 6 & 0.60 & 14.29 & 4.51 & 8.58 & 29.75 \\
\hline 4 & Halodule pinifolia & 218 & 24.60 & 6 & 0.60 & 14.29 & 6.02 & 11.45 & 50.34 \\
\hline 5 & Halophila ovalis & 110 & 12.42 & 4 & 0.40 & 9.52 & 3.19 & 6.07 & 28.00 \\
\hline \multirow[t]{2}{*}{6} & Cymodocea rotundata & 94 & 10.61 & 9 & 0.90 & 21.43 & 7.43 & 14.13 & 46.17 \\
\hline & Total & 886 & 100 & 42 & 4.20 & 100 & 52.59 & 100 & 300 \\
\hline
\end{tabular}

Transek III

\begin{tabular}{llllllllll}
\hline 1 & Thalassia hemprichii & 206 & 24.88 & 9 & 0.90 & 18.75 & 12.81 & 25.90 & 69.53 \\
2 & Enhalus acoroides & 95 & 11.47 & 10 & 1.00 & 20.83 & 13.75 & 27.81 & 60.11 \\
3 & Syringodium isoetifolium & 79 & 9.54 & 5 & 0.50 & 10.42 & 3.04 & 6.15 & 26.11 \\
4 & Halodule pinifolia & 11 & 1.33 & 4 & 0.40 & 8.33 & 0.78 & 1.58 & 11.24 \\
5 & Halophila ovalis & 313 & 37.80 & 8 & 0.80 & 16.67 & 8.67 & 17.53 & 72.00 \\
6 & Cymodocea rotundata & 89 & 10.75 & 8 & 0.80 & 16.67 & 5.67 & 11.47 & 38.88 \\
7 & Cymodocea serrulata & 35 & 4.23 & 4 & 0.40 & 8.33 & 4.73 & 9.57 & 22.13 \\
\hline & Total & 828 & 100 & 48 & 4.80 & 100 & 49.45 & 100 & 300 \\
\hline
\end{tabular}

Ket: $\mathrm{K}=$ Kerapatan, $\mathrm{KR}=$ Kerapatan Relatif, $\mathrm{F}=$ Frekuensi, $\mathrm{FR}=$ Frekuensi Relatif,

$\mathrm{P}=$ Penutupan, $\mathrm{PR}=$ Penutupan Relatif, INP = Indeks Nilai Penting

Tabel 2. Nilai Indeks Keanekaragaman

\begin{tabular}{lllllll}
\hline No. & Jenis Lamun & $\mathrm{ni}$ & $\mathrm{Pi}$ & $\mathrm{In} \mathrm{pi}$ & $\mathrm{pi} \ln \mathrm{pi}$ & $\mathrm{H}^{\prime}$ \\
\hline 1 & Thalassia hemprichii & 558 & 0.2409 & -1.4232 & -0.3429 \\
2 & Enhalus acoroides & 364 & 0.1572 & -1.8504 & -0.2908 \\
3 & Syringodium isoetifolium & 310 & 0.1339 & -2.0110 & -0.2692 \\
4 & Halodule pinifolia & 233 & 0.1006 & -2.2966 & -0.2310 \\
5 & Halophila ovalis & 423 & 0.1826 & -1.7002 & -0.3105 \\
6 & Cymodocea rotundata & 347 & 0.1498 & -1.8983 & -0.2844 \\
7 & Cymodocea serrulata & 81 & 0.0350 & -3.3531 & -0.1173 & \\
\hline & Total & 2316 & 1.00 & & -1.8462 & 1.8462 \\
\hline
\end{tabular}

Di transek III, nilai kerapatan tertinggi adalah jenis lamun $H$. ovalis sebanyak 313 individu/ $\mathrm{m}^{2}$ dengan kerapatan relatifnya $37.80 \%$ dan kerapatan yang terendah yaitu $C$. serrulata hanya 35 individu $/ \mathrm{m}^{2}$ 
dengan kerapatan relatifnya $4.23 \%$ (Tabel 1). Hal ini dimungkinkan karena karakteristik substrat yang berbeda antar transek, sehingga sebaran lamun tidak tersebar secara merata dan juga beberapa faktor lingkungan lainnya seperti aktivitas warga di sekitar lokasi penelitian (baik itu kegiatan nelayan setempat maupun untuk pariwisata) yang menyebabkan kondisi perairan dan lingkungan sedikit terganggu sehingga mempengaruhi ekosistem lamun. Hal ini juga menunjukkan kerapatan jenis lamun akan semakin tinggi bila kondisi lingkungan perairan tempat lamun tumbuh dalam keadaan baik. Menurut Kiswara (2004), kerapatan jenis lamun dipengaruhi oleh faktor tempat tumbuh dari lamun tersebut, seperti kedalaman, kecerahan, arus air dan tipe substrat.

Untuk frekuensi di transek I yang memiliki nilai tertinggi yaitu E. acoroides 1.00 dengan frekuensi relatifnya $26.32 \%$ dan yang terendah yaitu $H$. pinifoli 0.10 dengan frekuensi relatifnya $2.63 \%$. Di transek II nilai frekuensi tertinggi yaitu T. heemprichii 1.00 dengan frekuensi relatifnya $23.81 \%$ dan frekuensi terendah yaitu $H$. ovalis 0.40 dengan frekuensi realtifnya $9.52 \%$. Pada transek III nilai frekuensi tertingga yaitu $E$. acoroides 1.00 dengan frekuensi relatifnya $20.83 \%$ dan yang terendah yaitu $H$. pinifolia dan C. serrulata yaitu 0.40 dengan frekuensi realtifnya $8.33 \%$ (Tabel 1 ). Seperti yang telah diketahui, frekuensi merupakan peluang suatu jenis yang ditemukan dalam titik contoh yang diamati (Brower et al., 1989). Jadi T. hemprichii dan E. acoroides merupakan jenis yang dominasi dijumpai pada sejumlah plot pengamatan.
Penutupan lamun di transek I yaitu $51.20 \%$, transek II 52.59\% dan di transek III 49.45\%. Berdasarkan Keputusan MNLH No. 200 Tahun 2004 mengenai status padang lamun (Tabel 1), kondisi penutupan lamun di tiga transek tersebut masuk dalam kondisi yang kurang kaya/kurang sehat karena luas penutupannya berkisar di 3059.9\%. Rendahnya angka penutupan di pesisir Desa Lihunu diduga karena pantai Lihunu semakin ramai dikunjungi wisatawan dan tingginya kegiatan kapalkapal nelayan di kawasan ini, sehingga kekeruhan sulit dihindari. Seperti diketahui bahwa kekeruhan menghambat proses terjadinya fotosintesis. Menurunnya fotosisntesis berarti mengurangi pertumbuhan lamun. Nilai INP dari ketiga transek yaitu 300\%. Semakin tinggi nilai INP suatu spesies maka semakin tinggi peranan spesies tersebut dalam komunitasnya (Brower et al., 1989).

Hasil analisis keanekaragaman lamun dari keseluruhan transek dengan menggunakan indeks Shannon-Wienner seperti yang ditunjukkan di atas tergolong sedang karena nilai $H^{\prime}=1 \leq H^{\prime} \leq 3$ yaitu 1,85 (Tabel 2). Menurut Simamora (2012), semakin tinggi nilai indeks keanekaragaman suatu perairan maka semakin rendah pula tingkat pencemarannya. Bila dibandingkan dengan hasil penelitian tempat lain memiliki indeks keanekaragaman yang tergolong rendah. Hal ini dikarenakan jumlah spesies yang ditemukan sangat sedikit yaitu hanya 4 spesies (Rappe, 2010).

Jenis lamun yang ditemukan pada lokasi penelitian teridentifikasi secara visual dari perbedaan bentuk daun dan disajikan dalam Tabel 3 dan Gambar 1

Tabel 3. Perbedaan bentuk daun dari jenis lamun yang teridentifikasi

\begin{tabular}{lll}
\hline No & Jenis Lamun & Bentuk Daun \\
\hline 1 & T. hemprichii & lurus dan melengkung seperti sabit \\
2 & E. acoroides & panjang seperti pita \\
3 & H. ovalis & oval hingga membujur \\
4 & S. isoetifolium & bulat seperti lidi dengan ujung daunnya meruncing \\
5 & C. rotundata & lurus dengan ujung daun melengkung \\
6 & H. pinifolia & lurus dan halus \\
7 & C. serrulata & selempang yang menyempit dengan ujung daun seperti gergaji \\
\hline
\end{tabular}

Sumber: Kepel et al., (2012) 


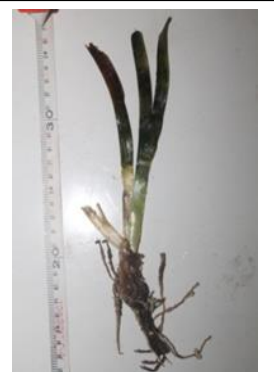

(a)

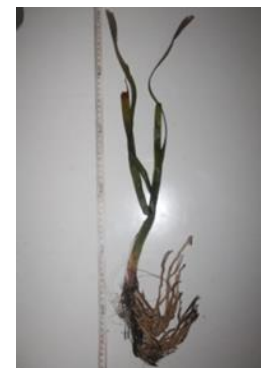

(b)

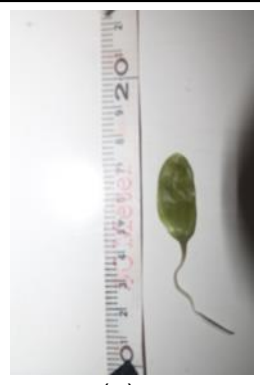

(c)

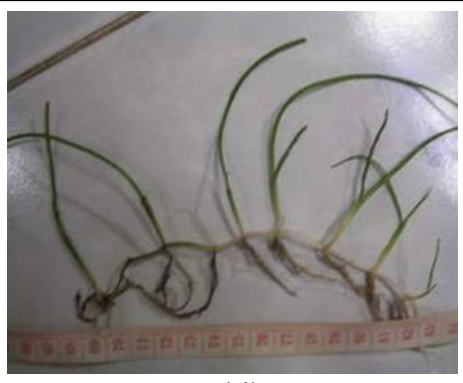

(d)

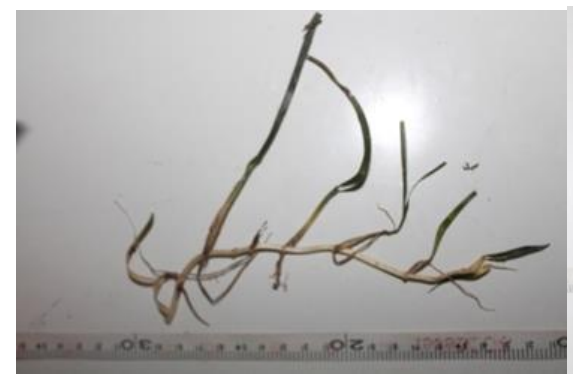

(e)

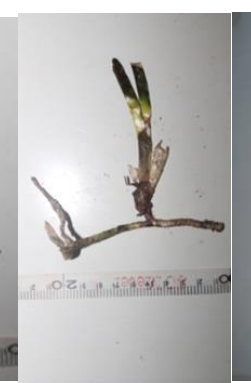

(f)

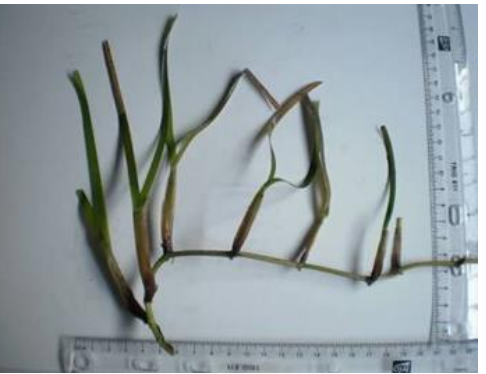

(g)

Gambar 1. Jenis-jenis lamun di lokasi penelitian: (a) Thalassia hemprichii (Ehrenberg) Ascherson, (b) Enhalus acoroides (L.f) Royle, (c) Halophila ovalis (R. Brown) Hooker, (d) Syringodium isoetifolium (Ascherson) Dandy, (e) Cymodocea rotundata (Ehrenberg) Ascherson, (f) Halodule pinifolia (Miki) den Hartog, (g) Cymodocea rotundata (Ehrenberg) Ascherson.

\section{Kesimpulan}

Berdasarkan penelitian yang telah dilakukan, maka dapat diambil kesimpulan:

a. Ada tujuh jenis lamun yang ditemukan di pesisir Desa Lihunu, yaitu dari family Hidrocharitaceae meliputi E. acoroides, T. hemprichii, H. ovalis dan $\mathrm{H}$. pinifolia. Family Cymodoceaceae yaitu C. rotundata, C. serrulata dan S. isoetifolium.

b. Jenis lamun $\mathrm{H}$. ovalis memiliki nilai kerapatan tertinggi yaitu 313 (individu/m2) di transek III, jenis lamun E. acoroides dan T. hemprichii memiliki nilai frekuensi tertinggi yaitu $1,00 \mathrm{di}$ transek I, II dan III dan jenis lamun T. hemprichii memiliki nilai penutupan tertinggi yaitu 19,52\% di transek II, serta jenis lamun T. hemprichii memiliki nilai INP tertinggi yaitu 90,72 di transek II. Indeks kenekaragaman lamun di Pesisir Desa Lihunu yaitu $H^{\prime}=1 \leq H^{\prime} \leq 3$ yaitu 1,85 menunjukkan bahwa keanekaragaman jenis tergolong sedang.

\section{Daftar Pustaka}

Brower JE, Zar, JH dan Ende CNV. 1989. Field and Laboratory Method for General Ecology Fourth Edition. McGraw-Hill Publication. Boston, USA.

Den Hartog, C. 1970. Seagrasses of The World. North Holland Publishing Amsterdam, London pp. 272.

Keputusan Menteri Negara Lingkungan Hidup. Kriteria Baku. 2004. Kerusakan dan Pedoman Penentuan Status Padang Lamun. Keputusan
Menteri Negara Lingkungan Hidup Nomor 200 Tahun 2004.

Kiswara. 2004. Kondisi padang lamun (seagrass) di perairan teluk Banten 1998-2001. [Skripsi]. Lembaga Penelitaian Oseanografi, Lembaga IImu Pengetahuan Indonesia. Jakarta.

Magurran. 1988. Metode Sampling Bioekologi. Bumi Aksara, Jakarta.

Nainggolan, P. 2011. Distribusi Spasial dan Pengelolaan Lamun (Seagrass) Di Teluk Bakau, Kepulauan Riau. [Skripsi], IPB: Bogor.

Nur, C. 2011. Inventarisasi Jenis Lamun dan Gastropoda yang Berasosiasi di Perairan Pulau Karangpuang, Mamuju, Propinsi Sulawesi Barat. [Skripsi]. Program Studi IImu Kelautan, Fakultas IImu Kelautan dan Perikanan, Universitas Hasanuddin. Makasar.

Phillips, R. C. dan E. G. Menez. 1988. Seagrasses. Smithsonian Institution Press. Washington.

Rappe, A. R. 2010. Struktur Komunitas Ikan Padang Lamun yang Berbeda di Pulau Barrang Lompo. [Skripsi]. IImu dan Teknologi kelautan. Universitas Hasanuddin. Makassar.

Simamora, K. 2012. Variabilitas Konsentrasi Klorofil-A Daun Suhu Permukaan Laut di Perairan Natuna. [Skripsi]. Departemen IImu dan Teknologi Kelautan, Fakultas Perikanan dan IImu Kelautan, Institut Pertanian Bogor.

Wood, E. J. F., W. E. Odum \& J. C. Zieman. 1969. Influence of The Seagrasses On the Productivity of Coastal Lagoons, Laguna Costeras. Un Simposio Mem. Simp. Intern. UU.N.A.M.-UNESCO, Mexico. 